\title{
Reconhecimento à Anna Justina Ferreira Nery: mulher e personalidade da história da enfermagem
}

\author{
Recognition to Anna Justina Ferreira Nery: woman and personality in nursing history \\ Reconocimiento a Anna Justina Ferreira Nery: mujer y personalidad en la historia de enfermería
}

\begin{abstract}
Maria Angélica de Almeida Peres ${ }^{1}$ (1) Pacita Geovana Gama de Sousa Aperibense ${ }^{2}$ (1)

Maria Lígia dos Reis Bellaguarda ${ }^{3}$ (1)

Deybson Borba de Almeida 4 (1)

Fernanda Batista Oliveira Santos ${ }^{5}$ (D)

Luciana Barizon Luchesi ${ }^{6}$ []
\end{abstract}

1.Universidade Federal do Rio de Janeiro,

Escola de Enfermagem Anna Nery. Rio de Janeiro, RJ, Brasil.

2.Universidade Federal do Rio de Janeiro, Campus Macaé Professsor Aloísio Teixeira. Macaé, RJ, Brasil.

3.Universidade Federal de Santa Catarina, Departamento de Enfermagem. Florianópolis, SC, Brasil.

4.Universidade Estadual de Feira de Santana. Feira de Santana, BA, Brasil.

5.Universidade Federal de Minas Gerais, Escola de Enfermagem. Belo Horizonte, MG, Brasil.

6.Universidade de São Paulo, Escola de Enfermagem de Ribeirão Preto. Ribeirão Preto, SP, Brasil
Autor correspondente:

Pacita Geovana Gama de Sousa Aperibense. E-mail: pacitageovana@yahoo.com.br.

Recebido em 08/06/2020.

Aprovado em 21/08/2020

\section{RESUMO}

Objetivo: Analisar os rituais de consolidação da figura de Anna Nery como enfermeira brasileira, heroína da Guerra do Paraguai, durante a trasladação de seus restos mortais à cidade de Cachoeira (BA). Método: Estudo histórico-social em fontes documentais impressas e fotográficas, pertencentes aos acervos do Centro de Documentação da Escola de Enfermagem Anna Nery da Universidade Federal do Rio de Janeiro, da Escola de Enfermagem da Universidade Federal da Bahia e da Hemeroteca Digital Brasileira da Biblioteca Nacional. Análise de informações impressas com base em Bardin, e na iconologia para as fontes imagéticas. Resultados: Revelam-se dois aspectos fulcrais, a legitimação de uma enfermeira heroína pelo Estado e o processo trasladatório com suas interfaces e aspectos históricos, políticos, econômicos e sociais. Destaca-se a construção de um ícone feminino, cívico e herói atrelada à efervescência da discussão de gênero que contribui para forjar a identidade profissiona no ensino de enfermagem. Conclusão e implicações para a prática: o estudo permite compreender os determinantes e implicações dos fatos históricos na biografia de Anna Nery para a Enfermagem e Enfermeiras, revelando os rituais do traslado de seus restos mortais e suas influências na construção da imagem social da mulher e da mulher enfermeira.

Palavras-chave: Enfermagem; História da Enfermagem; Guerras; Biografia; Rituais Fúnebres.

\section{ABSTRACT}

Objective: To analyze the rituals of consolidation of the character of Anna Nery as a Brazilian nurse, the heroine of the War of Paraguay, during the transfer of her remains to the city of Cachoeira (BA). Method: Socio-historical study in printed and photographic documentary sources, belonging to the collections of the Anna Nery Nursing School Documentation Center of the Federal University of Rio de Janeiro, Nursing School of the Federal University of Bahia and the Brazilian Digital Library of the National Library. Analysis of printed information was based on Bardin, and iconology for imagery sources. Results: Two key aspects are revealed, the legitimacy of a heroin nurse by the State and the transfer process with its interfaces and historical, political, economic, and social aspects. It highlights the construction of a female, civic, and hero icon linked to the effervescence of the gender discussion that contributes to shaping professional identity in nursing education. Conclusion and implications for practice: The study allows to understand the determinants and implications of historical facts in Anna Nery's biography for Nursing and Nurses, revealing the rituals of the transfer of her remains and their influences in the construction of the social image of women and nurse women.

Keywords: Nursing; History of Nursing; Wars; Biography; Funeral Rites.

\section{RESUMEN}

Objetivo: Analizar los rituales de consolidación de la figura de Anna Nery como enfermera brasileña, heroína de la Guerra del Paraguay, durante el traslado de sus restos a la ciudad de Cachoeira (BA). Método: Estudio histórico-social en fuentes documentales impresas y fotográficas, pertenecientes a las colecciones del Centro de Documentación de la Escuela de Enfermería Anna Nery de la Universidad Federal de Río de Janeiro, la Escuela de Enfermería de la Universidad Federal de Bahía y la Biblioteca Digital Brasileña de la Biblioteca Nacional. El análisis de la información impresa se basó en Bardin y en la iconología para las fuentes de imágenes. Resultados: Se revelan dos aspectos clave, la legitimación de una enfermera heroína por parte del Estado y el proceso de transferencia con sus interfaces y aspectos históricos, políticos, económicos y sociales. Se destaca la construcción de un ícono femenino, cívico y heroico vinculado a la efervescencia de la discusión de género que contribuye a forjar la identidad profesional en la educación de la enfermería. Conclusión e implicaciones para la práctica: El estudio permite comprender los determinantes e implicaciones de los hechos históricos en la biografía de Anna Nery para la Enfermería y Enfermeras, revelando los rituales del traslado de sus restos y sus influencias en la construcción de la imagen social de las mujeres y las enfermeras.

Palabras clave: Enfermería; Historia de la Enfermería; Guerras; Biografía; Ritos Fúnebres. 


\section{INTRODUÇÃO}

A História, concebida como ciência do conhecimento de fatos, atos e eventos vividos e viventes, ao ser desenvolvida pela sociedade no decorrer do tempo em espaços diversos, mostra aspectos específicos de cada história contada. Isto requer registro e documentação, que se consolidam pela importância e o valor dos seus nexos e circunstâncias como experiência humana. Cada pessoa, ao traçar sua história, defronta-se com influências que determinam seus feitos, os quais se atrelam a reveses existentes, especificamente, naquele período e momento social. Neste sentido, a história de vida de uma pessoa, em biografia, a eterniza, por meio das contribuições à história, seja a de uma profissão, seja de uma nação.

Pensar e escrever a história de vida de Anna Nery, considerada heroína da Enfermagem brasileira, permite-nos compreender os aspectos históricos desse campo de saber e analisá-lo enquanto profissão. Desse modo, as biografias são produções importantes na construção da história da profissão. Possuem determinantes contextuais e uma trama, imbricada e complexa de interesses e poderes, que perpassa pela reflexão dos aspectos históricos da profissão, seus rituais, símbolos e signos. ${ }^{1}$

Por conseguinte, na Enfermagem emergem, procedentes de várias partes do mundo, nomes ilustres pertinentes à organização profissional em cenários semelhantes de guerras, como a da Crimeia (1853-1856) e a do Paraguai (1864-1870), este último, um país vizinho ao Brasil. Pela natureza da sociedade, em seu caráter predominantemente machista, e diante de processos históricos, essas guerras chegaram a se ver envolvidas com questões de gênero e vulnerabilidades vigentes à época, ainda frágil de recursos humanos, materiais, métodos assistenciais e de trabalho em saúde.

Além disso, as biografias de enfermeiras têm sido utilizadas na educação de enfermagem com várias finalidades, como: ressaltar o desenvolvimento de uma área profissional específica; orientar a criação de escolas de enfermagem e associações profissionais; criar teorias de enfermagem; investigar os avanços sociais e políticos da profissão e, principalmente, abordar a história da enfermagem. ${ }^{1}$

Assim, o que interliga o historiador à história é a relevância das ações e eventos ocorridos, que deixaram registrado no imaginário social a sua referência. Nesta perspectiva, o objeto deste estudo abrange homenagens à Anna Justina Ferreira Nery, em fevereiro de 1979, período em que ocorreu a trasladação dos restos mortais dessa mulher, mãe e enfermeira ilustre, para a sua terra Natal, o município de Cachoeira, no Estado da Bahia, na região nordeste do Brasil.

Nesse sentido, o objetivo deste artigo é analisar os rituais de consolidação da figura de Anna Nery como enfermeira heroína da Guerra do Paraguai, no momento da transladação de seus restos mortais à cidade de Cachoeira, Bahia. A relevância da análise do evento de trasladação, aqui tratada, está no seu significado para a enfermagem brasileira, pois registra a destinação dos restos mortais de Anna Nery em mais uma homenagem, além de dar nome a hospitais, clínicas, ruas, viadutos, escolas, enfermarias e a um bairro, em diferentes regiões do país, reafirmando o reconhecimento dessa mulher, também como heroína nacional.

\section{Breve biografia de Anna Justina Ferreira Nery}

Anna Justina Ferreira Nery nasceu na Vila Nossa Senhora do Rosário do Porto de Cachoeira do Paraguaçu, na Bahia, em 13 de dezembro de 1814. Casou-se em 1837 com o Capitão de Fragata da Marinha do Brasil, Isidoro Antônio Nery, com quem teve três filhos, e ficou viúva em 1844. . $^{2,3}$

Em 1864, com o início da Guerra do Paraguai, seus dois filhos, que eram oficiais do Exército, e um irmão major seguiram para o campo de batalha. Anna Nery, então, escreveu uma carta dirigida ao Presidente da Província da Bahia, o conselheiro Manuel Pinho de Souza Dantas, a fim de acompanhar os filhos e o irmão, indo também para a região dos combates atuar nos hospitais de guerra. Anna Nery enfrentou dificuldades e preconceitos da época, especialmente àqueles em relação ao sexo feminino, superados por estar junto aos seus e pela sua paixão humanitária, expressada na carta em que solicitou permissão para ir à guerra como enfermeira, alegando o desejo de aliviar o sofrimento daqueles que iam lutar pela pátria. ${ }^{4,5}$

Anna Nery seguiu para os campos de batalha em 1865, na qualidade de enfermeira, compondo $04^{\circ}$ Batalhão de Voluntários do Corpo de Saúde do Exército, comandado por seu irmão, no qual desenvolveu atividades de cuidado aos feridos nos hospitais militares de Salto, Assunção, Corrientes e Humaitá, que tinham um número expressivo de soldados internados sob cuidados de um restrito quantitativo de irmãs de caridade, pertencente à congregação vicentina. Os relatos sobre seus feitos incluem a prestação de socorro aos soldados e organização de uma enfermaria em sua casa na Campanha, para o atendimento de saúde, com relatos de atendimento de soldados de ambos os lados da guerra. Além disso, foi vista muitas vezes no front, onde ela se mostrava com grande aptidão para incentivar e elevar a disposição e atitude moral das tropas. ${ }^{5}$

Em 1870, retornou ao Brasil, seu país de origem, que lhe recebeu com homenagens por toda a contribuição humanitária disponibilizada pela sua atuação como enfermeira no conflito paraguaio. Cognominada "Mãe dos Brasileiros", "Grande Irmã de Caridade Leiga" e "Heroína da Caridade" recebeu medalha de honra das mãos do Imperador do Brasil, além de outras homenagens no Rio de Janeiro e na Bahia. ${ }^{5-8}$

Continuou sua vida na Bahia, não existindo nenhuma informação exata sobre em qual cidade Anna Nery seguiu morando (Salvador ou Cachoeira), onde criou crianças órfãs, que trouxe do Paraguai, fato que na literatura científica varia em número de 3 a 6 crianças por ela criadas. Mudou-se para a cidade do Rio de Janeiro, na década de 1870, em decorrência da transferência do seu filho e então Capitão do Exército, Antônio Néri. Faleceu nesta cidade, em 20 de maio de 1880, aos 65 anos de idade e foi sepultada no Cemitério São Francisco Xavier, no bairro do Caju, zona portuária do Rio de Janeiro. ${ }^{2,3}$ Inexistem registros históricos, localizados até a presente data, de que Anna Nery atuou como Enfermeira ou com práticas de cuidados após a Guerra do Paraguai. 
Após a criação, em 1922, da Escola de Enfermeiras do Departamento Nacional de Saúde Pública pelo governo federal, ainda na vigência da Missão Parsons, que veio a difundir na sociedade brasileira o modelo de ensino de enfermagem angloamericano, houve renomeação dessa escola, em 1926, para Escola de Enfermeiras Dona Anna Nery. ${ }^{9}$ A fim de manter sua memória, esta Escola instituiu uma romaria ao seu túmulo, em 1926. A cerimônia era anualmente realizada na data de seu falecimento (20 de maio), quando professoras e estudantes levavam flores para prestar homenagem a esta heroína brasileira, fato veiculado por diversas vezes no texto jornalístico. ${ }^{10,11}$

A memória de Anna Nery exalta na sociedade brasileira a enfermeira pioneira, reconhecida como precursora da Cruz Vermelha Brasileira, em 1956, em nome de quem foram erguidos monumentos que perpetuam lembranças como "Irmã de Caridade Leiga", cujas fontes históricas remetem à ideia de orgulho patriótico por sua atuação. ${ }^{5,11}$

Nos idos de 1979, os restos mortais de Anna Nery receberam o tratamento para trasladação até sua cidade natal, em homenagens que revitalizaram na sociedade brasileira do século $X X$ sua memória.

\section{MÉTODO}

Pesquisa documental, sócio-histórica, a partir do marco temporal circunscrito ao ano de 1979, quando ocorreu o requerimento de traslado dos restos mortais de Anna Nery para a cidade de seu nascimento.

\section{Fontes documentais}

Os acervos históricos de busca documental foram o Centro de Documentação (CDOC) da Escola de Enfermagem Anna Nery (EEAN) da Universidade Federal do Rio de Janeiro (UFRJ), o acervo da Escola de Enfermagem da Universidade Federal da Bahia (EEUFBA), a Hemeroteca Digital Brasileira da Biblioteca Nacional e literatura científica sobre o tema.

Os critérios de seleção das fontes consideraram os documentos referentes ao processo de trasladação dos restos mortais de Anna Nery e fontes produzidas sobre o tema no ano do recorte temporal definido. As fontes seguiram a classificação de avaliação e relevância para o estudo histórico, referentes à procedência direta, à intencionalidade voluntária, à qualidade do material e à quantidade do material impresso encontrado. Assim, chegou-se a 23 documentos, sendo 12 de origem hemerográfica e 11 arquivísticos. Para a análise consideraram-se 18, pois 5 foram excluídos por não apresentarem relação direta com o ato da trasladação em si.

\section{Tratamento e análise de dados}

As fontes localizadas foram fotocopiadas e organizadas em arquivo digital, utilizando-se uma matriz com os seguintes dados: descrição do tipo, autor, local e data, acervo de origem e tema. Posteriormente, fez-se a leitura do material, separando-se em planilha excel as informações pertinentes ao processo de transladação dos restos mortais de Anna Nery. A organização, tratamento e análise dos dados coletados aconteceram entre novembro de 2019 e janeiro de 2020 com triangulação das fontes. ${ }^{12}$

Utilizou-se a análise de conteúdo defendida por Bardin para as informações impressas e a iconologia para a análise das fontes imagéticas. $O$ tratamento dos dados se deu pela análise por similitude e pertinência do conteúdo. ${ }^{13}$ Realizou-se o recorte dos textos em unidades, o que levou à categorização para a análise temática e registro dos dados, organizando os dados de forma padronizada e equivalente. O Reagrupamento por analogia foi composto, o que nos possibilitou a identificação das unidades de registro para realizarmos a contagem frequencial e de aparição e similitude, resultando nas unidades de significação do tema em estudo. A análise interpretativa do corpus se deu pela análise de conteúdo temática, guardando a cronologia dos fatos e confluiu nas categorias: "Rituais que antecederam o traslado dos restos mortais de Anna Nery para Cachoeira" e "Legitimação de Anna Nery como enfermeira heroína pelo Estado".

O estudo obedeceu às normas da Resolução no 510/2016 e recebeu aprovação de Comitê de Ética em Pesquisa da UFRJ pelo parecer de n. 2.763.279/18

\section{RESULTADOS}

\section{Rituais que antecederam o traslado dos restos mortais de Anna Nery para Cachoeira}

O processo de trasladação dos restos mortais de Anna Nery envolveu as Universidades Federais do Rio de Janeiro e da Bahia, as três forças militares do país (Exército, Marinha e Aeronáutica) e o estado da Bahia e do Rio de Janeiro.

O Jornal do Brasil (RJ), uma semana antes, em 27 de janeiro de 1979, anunciava em uma pequena nota na seção "Primeiro Caderno" que os despojos de Anna Nery seriam trasladados à Cachoeira. A notícia, fazendo referência a como se organizaria a solenidade, cuja recepção ocorreria do estádio da cidade, dava indícios de sua magnitude pelo envolvimento e presença de autoridades civis, militares e religiosas.

A Comissão de Trasladação foi constituída por dois grupos de trabalho, um no Rio de Janeiro e outro na Bahia. A representação do nordeste teve como presidente o Vice-governador do Estado da Bahia, Edwaldo Brandão Correia e foi constituída por: Cardeal arcebispo da arquidiocese de Salvador, D. Avelar Brandão Vilela; Vice-almirante da Marinha do Brasil Gabriel de Araújo Bastos; Major-Brigadeiro do Exército Brasileiro Ciro de Souza Valente; General do Exército Brasileiro Otávio Pereira da Costa; Reitor da Universidade Federal da Bahia, Augusto da Silveira Mascarenhas; Diretora da EEUFBA, Clara Wolfovitch; Prefeito de Cachoeira, Ariston Mascarenhas; escritora e feminista, Edith Mendes da Gama e Abreu. Pela região sudeste compuseram a Comissão: o ex-reitor da então Universidade do Brasil em duas gestões (1948-1950 e 1951-1966) o professor Pedro Calmon, o ex-Ministro do Tribunal Federal de Recursos (TFR), José Joaquim Moreira Rabello e a diretora da EEAN à época, professora Cecília Pecego Coelho. 
A programação preparada pelo Governo do Estado da Bahia, prevista para o dia 4 de fevereiro de 1979, contemplava o transporte de avião dos restos mortais de Anna Nery do Rio de Janeiro para Salvador, depois de helicóptero até Cachoeira, Cortejo e Sessão Cívica nesta cidade, finalizando com cerimônia religiosa no local em que ficaria em definitivo - a Igreja Matriz de Nossa Senhora do Rosário, situada ao lado da sua antiga residência, local onde Anna Nery viveu parte de sua vida.

Antecederam à programação, preparativos e homenagens que foram levadas a efeito no Rio de Janeiro, a começar pelo processo de exumação dos restos mortais de Anna Nery, realizado no dia 01 de fevereiro de 1979, no Cemitério São Francisco Xavier, sob liderança do seu administrador, Paulo Francisco Rodrigues e na presença de dez testemunhas, dentre as quais identificaram-se: José Joaquim Moreira Rabello, Ex-ministro do Tribunal Federal de Recursos e natural de Cachoeira; Vanda C. Amado, representando a Santa Casa de Misericórdia da Bahia; Cecília Pecego Coelho, Diretora da EEAN; Ciley Chaves Rhodus, Vice-diretora da EEAN; Elvira De Felice Souza e Maria Dolores Lins de Andrade, ambas ex-diretoras da EEAN; Luciano Nilo de Andrade, esposo de Maria Dolores; Dahas Zarur, Diretor da Santa Casa de Misericórdia do Rio de Janeiro.

Ao noticiar a exumação, o Jornal Última Hora (RJ), de 02 de fevereiro de 1979, informou que, além das personalidades citadas, estava presente "um grande número de alunas de enfermagem e enfermeiras", e que o Diretor da Santa Casa de Misericórdia exaltou, em algumas palavras, a "missão sublime" de Anna Nery durante sua permanência na Guerra do Paraguai.

Os restos mortais de Anna Nery foram colocados em uma urna de jacarandá e prata polida feita nos moldes dos baús de noivas do século XVIII para combinar com a arquitetura barroca da Igreja da Matriz de Cachoeira, onde ficaria exposta. A urna foi oferecida pela Universidade Federal da Bahia e continha duas placas (uma na parte superior e outra na frente da urna) com as seguintes inscrições: "Restos mortais de Ana Nery, mãe dos Brasileiros na Campanha do Paraguai. Homenagem da Universidade Federal da Bahia, 1979" (superior) e, "Aqui está Ana Nery vencendo as trevas da morte e a distância dos séculos para receber de nós outros o que lhe deve à posteridade" (frente).

Do cemitério, a urna com os restos mortais de Anna Nery foi levada para o Pavilhão de Aulas da EEAN, onde foi celebrada uma missa. A urna ficou exposta à visitação pública do dia 1 ao dia 4 de fevereiro, na sala da Associação de Ex-alunos da Escola junto a uma coroa de flores oferecida por esta instituição. A lista de presença mostra o total de 103 visitantes, entre eles, professores, alunos e funcionários da EEAN, Presidente da Associação Brasileira de Enfermagem (ABEn) Nacional e da ABEn Seção Rio de Janeiro, representantes da Faculdade de Enfermagem da Universidade do Estado do Rio de Janeiro (UERJ), outros enfermeiros, repórteres e pessoas da sociedade em geral.

$\mathrm{Na}$ fotografia apresentada na Figura 1 vê-se sobre a urna uma bandeira da EEAN em tamanho reduzido e, atrás, do lado direito, a bandeira em tamanho oficial. Na frente da urna está o livro para assinaturas dos visitantes.
A imprensa carioca fez o anúncio da trasladação com notas destacadas e as seguintes mensagens: "Urna de Ana Nery ficará em Cachoeira" (Jornal do Brasil, 27/01/1979), "Cinzas de Ana Nery vão à Bahia" (Jornal do Brasil, 01/02/1979), "Despojos de Ana Néri serão levados domingo para a Bahia" (O Globo, 02/02/1979), "As cinzas de Ana Neri voltam domingo à Bahia" (Última Hora - RJ, 02/02/1979), "Adeus à Ana Neri” (Jornal do Commercio - RJ, 05/02/1979), "Restos mortais de Anna Nery acolhidos em sua terra natal” (O Dia - RJ, 06/02/1979).

\section{Legitimação de Anna Nery como enfermeira heroína pelo Estado}

Na manhã do dia 4 de fevereiro de 1979, a urna, acompanhada por professores, dentre eles a Diretora da EEAN e o historiador e ex-reitor da UFRJ, Pedro Calmon e convidados, foi levada ao aeroporto Santos Dumont e entregue ao representante da Aeronáutica responsável pelo transporte à Bahia.

Os restos mortais de Anna Nery seguiram no avião de patrulha P-95 da Força Aérea Brasileira (FAB), acompanhados por Cecília Pecego e Pedro Calmon, além do escritor Adonias Filho, na qualidade de presidente do Conselho Nacional de Cultura. Chegando em Salvador às 11:30h do mesmo dia, um domingo, foram recebidos com as devidas honras, por duas guardas oficiais da Marinha e da Aeronáutica, ficando na Base Aeronaval de São Pedro da Aldeia sob a guarda de dois militares.

A Figura 2 mostra dois militares levando a urna do avião para a capela da base aérea, onde o Capelão, Padre Saul Bianchi exaltou os feitos de Anna Nery, destacando a importância de mostrar à juventude "as grandes personalidades do país, no passado e no presente [...]". Estiveram presentes, à ocasião, o Comandante da Base Aérea, Coronel Lair da Silva Andrade Major Brigadeiro Ciro-Valente; Comandante do Comando

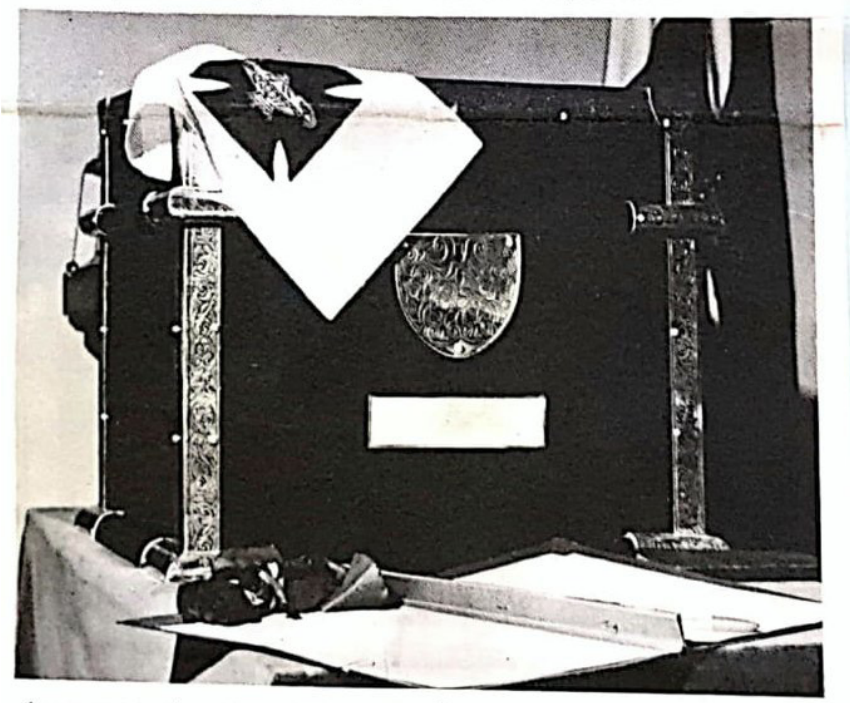

A urna contendo as cinzas de Anna Nery, quando em exposiçāo no Rio, coberta pela bandeira da Escola que leva seu nome.

Figura 1. Urna com restos mortais de Anna Nery. Fonte: Jornal Brasileiro de Enfermagem, abril de 1979. 


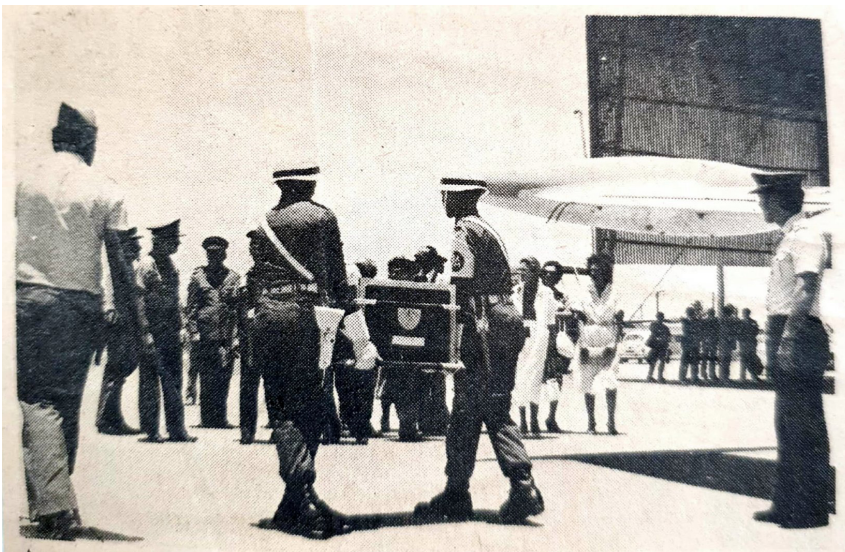

A urna chegou ao Aeroporto Militar, onde houve uma solenidade

Figura 2. Chegada da urna com os restos mortais de Anna Nery em Salvador no dia 04/02/1979.

Fonte: Jornal da Bahia, 05/02/1979.

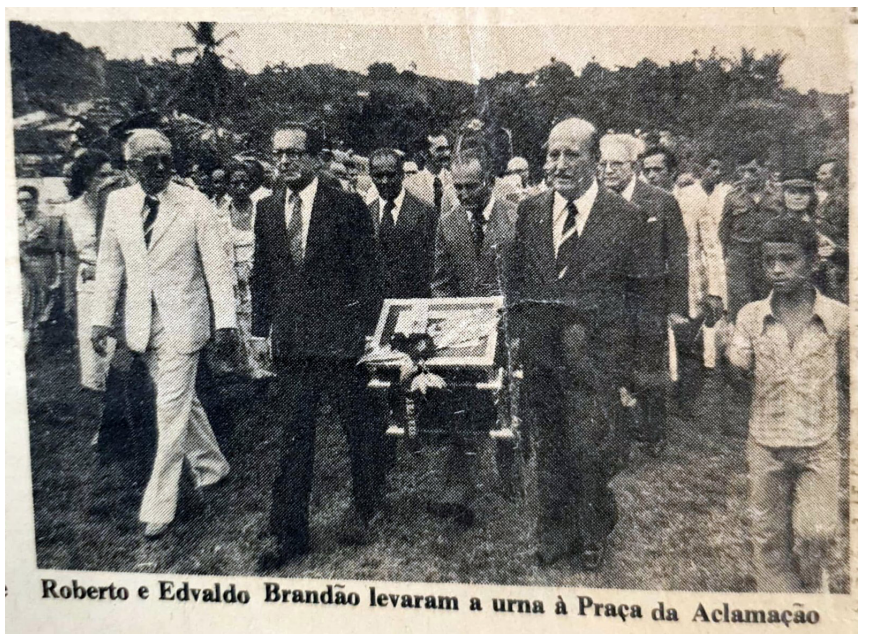

Figura 3. Autoridades transportando os restos mortais de Anna Nery.

Fonte: Jornal da Bahia, 05/02/1979.

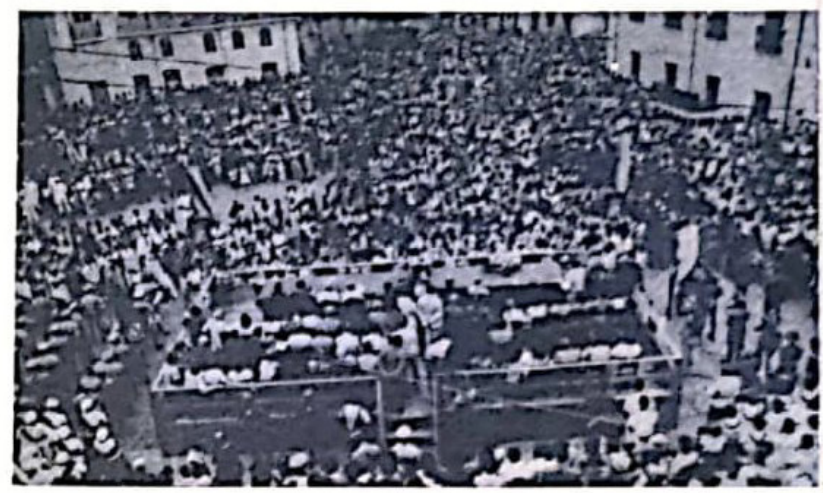

A Praģa da Aclamaçāo foi pequena para conter a populaçēo de Cachoeira, que recebia emocionada a sua grande herolna.

Figura 4. Praça da Aclamação em Cachoeira na homenagem à Anna Nery.

FONTE: Jornal Brasileiro de Enfermagem, Abril de 1979.
Costeiro, General Otávio Rocha; Comandante da VI Região Militar, Capitã Enfermeira do Exército Jandira Meireles Mendonça (atuante na $2^{\mathrm{a}} \mathrm{GM}$ ), nascida em Cachoeira, na mesma casa em que anteriormente residiu Anna Nery; Diretor do Museu de Arte Sacra da Bahia, Valentin Calderón.

A saída da urna com os restos mortais de Anna Nery de Salvador para a cidade de Cachoeira ocorreu em helicóptero da Marinha, com guarda de outros quatro helicópteros navais comandados pelo Almirante José Maria de Amaral Oliveira. O helicóptero de prefixo N7035 pousou no Estádio Municipal de Cachoeira às 16:30h aos primeiros acordes de "Cisne Branco", Hino da Marinha de Guerra Brasileira. A retirada da urna do helicóptero foi feita por soldados do exército, à vista de autoridades e cidadãos de Cachoeira e entregue ao Governador e ao Vice-governador da Bahia, que iniciaram o cortejo até a Igreja da Matriz, com revezamento de muitas outras autoridades.

A Figura 3 foi publicada pelo jornal "A Tarde" de SalvadorBahia, em 05 de fevereiro de 1979, com o registro da participação popular no evento que apresentou: desfile cívico, bandas marciais, colégios, agremiações literárias e "estudantes com os nomes de cachoeiranos que dignificaram sua terra, mostrando que os filhos ilustres de Cachoeira estavam presentes esperando sua maior filha". O Jornal da Bahia também descreve com detalhes o evento que sensibilizou a cidade de Cachoeira: "O cortejo, tendo à frente o governador Roberto Santos e o vice Edvaldo Brandão, percorreu as ruas Dr. Virgílio Reyz e 25 de julho, rumo a Praça da Aclamação, onde a urna seria apresentada a população. Na praça, ao som do "Hino a Cachoeira", centenas de pessoas puderam ver a urna em jacarandá, onde se encontram os despojos da pioneira da enfermagem no Brasil (e que teve participação marcante no socorro aos feridos brasileiros na guerra do Paraguai) Ana Justina Ferreira Nery, Ana Neri, "A Mãe dos Brasileiros".

A reportagem, publicada no Jornal da Bahia de 05 de fevereiro de 1979, também descreve com detalhes a organização do local e revela que a mesma frase usada na frente da urna foi afixada em uma placa, em frente ao prédio da Prefeitura Municipal de Cachoeira. Também é possível notar no registro jornalístico que a emoção e os sentimentos estavam bastante vivos naqueles que acompanhavam o cortejo, conforme registro: "A [frase] exprimia bem o que a cidade viveu ontem: uma tarde em que todos reverenciavam a heroína brasileira como se ela estivesse presente".

A Figura 4 é um registro fotográfico publicado na reportagem do Jornal Brasileiro de Enfermagem se observa que se armou um palanque na Praça da Aclamação para as comemorações. Foi possível identificar que estavam presentes, além das autoridades já citadas, o Prefeito e Vereadores de Cachoeira; a representante do reitor da UFBA, a senhora Mascarenhas; o Cônsul de Portugal na Bahia; membros do Conselho Estadual de Cultura da Bahia; a enfermeira baiana, à época, Presidente do Conselho Federal de Enfermagem (COFEn), Maria Ivete Ribeiro de Oliveira; o vigário de Cachoeira, Padre Fernando Carneiro; a Diretora da EEUFBA, Clara Wolfovitch; a Presidente do Conselho Regional 
de Enfermagem da Bahia (COREn-BA), Sonia Maria Passos da Silva Pinto; a professora da EEAN, Haydee Guanais Dourado; as enfermeiras e ex-alunas da EEAN, Radcliff Dourado e Anita Dourado Teixeira e a Diretora da Escola de Música da Pontifícia Universidade Católica da Bahia, Dulce Calmon de Brito.

A urna foi colocada no centro de uma grande mesa montada sobre o palanque da praça, onde sentaram-se as autoridades e convidados para a cerimônia cívica. A programação (Figura 1) obedeceu aos seguintes itens: 1. Execução do Hino à Cachoeira; 2. Palavra do Ministro J.J. Moreira Rabelo, em nome de Cachoeira; 3. Palavra da acadêmica Edith Mendes da Gama Abreu, em nome da mulher baiana; 4. Palavra do General Octávio Costa, em nome das Forças Armadas; 5 . Palavra de encerramento pelo Governador do Estado, professor Roberto Santos; 6 . Execução do Hino Nacional Brasileiro.

Após a cerimônia cívica, o cortejo seguiu até a igreja da Matriz de Nossa Senhora do Rosário, e os restos mortais foram depositados com a urna no ossuário da sacristia da mesma igreja, onde Anna Nery foi batizada.

A matéria jornalística publicada em 05 de fevereiro de 1979 no jornal A Tarde, intitulada "Cinzas de Ana Nery são entregues à sua terra natal", destaca a iniciativa do governo do estado da Bahia e o apoio recebido dos militares para tal feito. Ao apresentar uma síntese dos discursos das autoridades presentes, a matéria remete a termos que incorporam um idealismo, um patriotismo, constatado nas falas masculinas. $O$ governador destacou a "satisfação cívica que sentia" de realizar tal feito em seu governo. O ministro Moreira Rabelo destacou os feitos de Anna Nery e seu significado na formação do povo brasileiro. $O$ General Otávio Costa destacou o exemplo de Anna Nery para o povo. $O$ reforço à imagem de uma heroína e seu ato de civismo em prol do país foi a tônica das referências dos discursos das autoridades governamentais.

\section{DISCUSSÃO}

Os anos de 1974 a 1979 foram marcados pelo governo do general Ernesto Geisel como presidente da República e pela sua declaração, evocando introdução à abertura política, após os duros anos de quebra democrática no governo brasileiro. E esta democracia viria de forma lenta e gradual, concretizandose em 1985 com as "Diretas já" e votação nas urnas pelo povo brasileiro. Ademais, considere-se que a economia brasileira foi tratada, em comentários técnicos à época, como se os brasileiros vivessem o que foi denominado de "o milagre econômico" e que este havia chegado ao fim. A violência repressiva e a ausência de liberdades civis e públicas havia conduzido o país a uma situação insustentável sob o ponto de vista da manutenção do regime de ditadura militar, fazendo com que diversos setores da sociedade brasileira (progressistas da Igreja Católica, burguesia industrial, movimento estudantil, movimento metalúrgico e artistas) se organizassem como oposição ao militarismo. ${ }^{14}$

É possível inferir que a transladação dos restos mortais de Anna Nery para a Bahia, em um tempo de ditadura militar, serviu de "pano de fundo" para reforçar valores cívicos e ufanistas para atender dois objetivos: melhorar a imagem do governo $e$ reforçar a identidade profissional das enfermeiras. Da mesma forma, é possível inferir que o governo brasileiro pode ter tido interesses estratégicos na iconização de Anna Nery, podendo servir para uma saída honrosa da guerra, já que muitos soldados brasileiros foram mortos e outros tantos retornaram inválidos da desmobilização militar ${ }^{15-17}$.

Uma mulher como Anna Nery, considerada uma heroína, configura o que pode ser facilmente relacionado, no imaginário popular, como ponto de referência e força de identificação coletiva das mulheres, ainda tão oprimidas na ocasião. Esta construção de Anna Nery como heroína se deve, possivelmente, a muitas mobilizações de coragem, afetos e ideais coletivos, que também correspondem a um modelo religioso ético, moral e ideológico, engendrado tanto pelo regime político quanto pela população brasileira.

Ainda que sua motivação inicial tenha sido o desejo de acompanhar sua família ${ }^{18}$, expresso na carta em que solicitou permissão para ir à guerra como enfermeira, alegando o desejo de aliviar o sofrimento daqueles que iam lutar pela pátria, Anna Nery lutava consigo mesma para sobrelevar sentimentos que incluíam a ausência de seus filhos, medo de perdê-los na guerra, além da solidão que enfrentava pela situação de viuvez, que, à época, enfrentava. Destaca-se que os sentimentos motivadores desta mulher não eram menores que sua ética em abraçar uma ação voluntária na guerra, dedicando-se ao cuidado dos feridos. Tanto assim, que Anna Nery não desistiu quando perdeu seu filho e seguiu adiante, permanecendo em prol da vida de tantos anônimos, conforme evidenciado em registros da época ${ }^{19}$. Não obstante, ser viúva foi uma condição favorável naquele momento histórico, pois dava a Anna Nery certa liberdade para conviver no espaço público de domínio masculino.

O uso da figura de heroína da pátria evidenciado na trasladação dos restos mortais de Anna Nery, por mais que soe como uma estratégia para a reconsideração dos cidadãos brasileiros na moralização dos feitos do Estado em abertura política, rompe com o radicalismo da época, incluindo a dominância de homens e minimização da atividade participativa de mulheres.

Reflitamos que, nesse momento, foi erguido mais um marco em torno da cuidadora de soldados em guerra. Inegável destaque e devida homenagem à brasileira Anna Nery como figura de grande dotação em qualidades especiais para o correspondente feitio feminino e distinção como mulher intrépida e de diferente senso político-social para o seu tempo.

Anna Nery tem em sua trajetória vivida a permanência dos atos, não em prol de uma identidade profissional, visto que não foram localizados registros de uma atuação como enfermeira ao retornar da guerra, mas sob a influência de uma identidade do cuidado. Por isto, a eternização se registra em sua história de vida em face dos resultados de suas atitudes. Em seu viver, optou por cuidar de feridos diante de circunstâncias que hoje a fazem perene nas memórias e espelham exemplares e boas práticas de cuidar com a presença do humano. Anna Nery foi reverenciada por sua prática como enfermeira de guerra, 
encontrando-se com a profissão de enfermagem brasileira, implantada no século XX.

Em organização para a última homenagem, autoridades estatais, religiosas e militares, além de um movimento intelectual de autoridades das universidades federais (Bahia, Rio de Janeiro) se reuniram diante dos restos mortais de Anna Nery. Teve destaque o apoio da EEAN e de outras autoridades governamentais e universitárias, representantes da enfermagem (ABEn, COFEn e COREns), que compareceram a essa homenagem, participando deste ritual, acompanhando a exposição da urna com os restos mortais e ouvindo os discursos político-sociais, os quais conclamavam a população na solenidade.

O Estado brasileiro buscou legitimar, com toda a honraria, a figura da enfermeira da Guerra do Paraguai, facilitando a veiculação, em mídias sociais, de notas sobre a exumação dos restos mortais de Anna Nery em jornais de grande circulação, com fotos documentais relevantes. O uso de expressões "Mãe dos brasileiros", "Heroína Voluntária da Guerra do Paraguai", "Heroína Baiana" e "Fundadora da Enfermagem brasileira" mostram a abnegação e qualificação de Anna Nery. Os ritos de transladação, aqui descritos, resgatam ideais da enfermeira brasileira, ressaltados sob o legado de Anna Nery até, aproximadamente, a década de 1950, como figura abnegada, feminina/materna, que foram utilizados no discurso de muitas Escolas de Enfermagem Brasileiras para recrutamento de candidatas a enfermeiras que, assim como Florence Nightingale, buscavam, através do discurso feminino/maternal, idealizar a imagem da mulher enfermeira.

Entretanto, na década de 1970, o discurso da Enfermagem Brasileira tinha pautas avançadas como a organização da pósgraduação stricto sensu, mudanças curriculares, criação dos Conselhos Regionais e Federais e do código de deontologia da enfermagem. Se, por um lado, destaca-se a visibilidade que o rito promoveu para a enfermagem brasileira, por outro lado, esses estereótipos já não se alinhavam com os avanços da profissão, evidenciando uma lacuna entre a realidade da profissão de enfermeira em 1979 e o ideal, que o Estado passou nos ritos de trasladação.

Destaca-se ainda, a presença da feminista, educadora e literata, primeira mulher a ocupar uma cadeira na Academia de Letras da Bahia, Edith Mendes da Gama Abreu, para representar a mulher baiana e discursar no evento, que envolvia o ato cívico de recepção dos restos mortais de Anna Nery. O discurso de Edith Abreu foi publicado, na íntegra, na edição de 18 de fevereiro de 1979, do Jornal da Bahia. Nele, destaca-se a atuação de Anna Nery durante a guerra e, também, seus feitos históricos, voltados à sua cidade natal:

"O patriotismo não tem sexo. O civismo, o nativismo verdadeiro, não tem sexo. Não é preciso ser homem para ser capaz de rasgos de bravura, a prova é que mulheres como Ana Nery, Maria Quitéria, Joana Angélica dentre outras, se igualaram, se não superaram - os homens na defesa pelo solo pátrio [...] Toda mulher perfeita e verdadeira, guarda em seu coração um sentimento de bravura, que pode ser acionado sempre que seus filhos estejam em perigo - mesmo que, estes filhos, sejam simbólicos - e foi isso o que Anna Nery fez: defendeu os filhos dos outro, que lutavam e até foram feridos em guerra" (Doc.16, Quadro 1)

A reassunção da heroína de guerra, Anna Nery, ocorre pela celebração de seus feitos, de sua participação ativa e de caráter transformador da realidade. É assim que Anna Nery se mostra celebridade, enquanto mulher e enfermeira no Brasil do século XIX. Observa-se nas publicações midiáticas, por meio de discursos e relatos gravados na memória daqueles que vivenciam ou mesmo aplaudem os feitos de alguém, que os vínculos afetivos, para descrição ou narrativas históricas, advêm de imagens e de discursos, que registram e fazem acontecer a permanência dos feitos. E o paradoxo da morte faz surgir, ou melhor, faz permanecer, transcender, o simbolismo de todos os feitos, neste estudo, de Anna Justina Ferreira Nery.

Embora Anna Nery tenha sido uma enfermeira voluntária, sua atuação em seu tempo, em pleno século XIX, deu visibilidade ao trabalho feminino de cuidar do ser humano. Tudo isso foi representado na trasladação pela notoriedade das autoridades que se fizeram presentes e que, no campo da enfermagem, foram de acadêmicas de enfermagem até entidades representativas da profissão.

A personagem Anna Nery transpassa do presente de seu tempo para este presente e ainda tem muito a construir no futuro desta profissão, pois reúne emblematicamente atributos veneráveis à sociedade, com o intuito de continuar constituindo melhores enfermeiras e excelentes práticas profissionais. Outrossim, estudando o traslado dos restos mortais de grandes "Homens e Mulheres" da nossa história, aproximamos a sociedade brasileira desses heróis e dentre eles, a memória física dessas insignes pessoas, que vão além do tempo em que as enaltecemos e buscam a saudade da sua correspondente terra natal.

A conclamação de Anna Nery é ratificada quando emerge mais uma vez como vulto nacional no registro jornalístico à época de, pelo menos, oito jornais diferentes, demonstrando que as notícias não só descrevem e narram, como atribuem exteriorização e fixação aos acontecimentos, constituindo-os como documento histórico. ${ }^{20}$

Por ser agraciada em seus méritos com o título de enfermeira, o referido evento teve o pronunciamento de discursos enaltecedores de seus méritos e significados dados ao cuidado de enfermagem. Sem hesitação pode ser dito que, no traslado dos restos mortais de Anna Nery, os discursos das autoridades presentes legitimaram o seu reconhecimento como uma mulher de distinta exemplaridade, retomando o discurso sobre o ideal do enfermeiro, predominante em décadas anteriores, mas que reverbera no ideário social até os dias de hoje. Destaca-se ainda, o efeito da visibilidade da enfermagem brasileira no texto jornalístico.

Dentro desse contexto, a profissão de enfermagem no Brasil se empenhou, por meio de seus representantes e da escola que 
Quadro 1. Fontes analisadas no estudo.

\begin{tabular}{|c|c|}
\hline Doc. & Fonte / Tipo/Localização/ Data \\
\hline 1 & $\begin{array}{l}\text { Urna de Ana Nery ficará em Cachoeira. Jornal do Brasil (RJ) - seção: Primeiro Caderno - sábado, 27/01/1979. } \\
\text { Localização hemeroteca digital da Biblioteca Nacional: http://memoria.bn.br/DocReader/030015_09/193394 }\end{array}$ \\
\hline 2 & $\begin{array}{l}\text { Cinzas de Ana Nery vão à Bahia. Jornal do Brasil - seção: Primeiro Caderno - quinta-feira, 01/02/1979. Localização } \\
\text { hemeroteca digital da Biblioteca Nacional: http://memoria.bn.br/DocReader/030015_09/193705 }\end{array}$ \\
\hline 3 & $\begin{array}{l}\text { Homenagem à Anna Nery Mãe dos Brasileiros. Texto elaborado pela professora da EEAN, Maria Madalena } \\
\text { Werneck. Documento, suporte papel. CDOC/EEAN/UFRJ, Caixa: Anna Nery. 01/02/1979 }\end{array}$ \\
\hline 4 & $\begin{array}{l}\text { Lista de assinaturas dos presentes na Visitação à Urna de Anna Nery. Documento, suporte papel. CDOC/EEAN/ } \\
\text { UFRJ, Caixa: Anna Nery. 1/02/1979 a 4/02/1979 }\end{array}$ \\
\hline 5 & $\begin{array}{l}\text { Despojos de Ana Néri serão levados domingo para a Bahia. O Globo. Recorte de Jornal, CDOC/EEAN/UFRJ, Caixa: } \\
\text { Anna Nery. 02/02/1979, data e identificação do jornal manuscrita. }\end{array}$ \\
\hline 6 & $\begin{array}{l}\text { As cinzas de Ana Neri voltam domingo à Bahia. Última Hora. Recorte de Jornal, CDOC/EEAN/UFRJ, Caixa: Anna } \\
\text { Nery. 02/02/1979, data e identificação do jornal manuscrita. }\end{array}$ \\
\hline 7 & Termo de Trasladação do Cemitério São Francisco Xavier. Documento. CDOC/EEAN/UFRJ. 04/02/1979 \\
\hline 8 & $\begin{array}{l}\text { Convite do Governo da Bahia com o Programa de Trasladação dos restos mortais de Anna Nery. Documento, } \\
\text { CDOC/EEAN/UFRJ. 04/02/1979 }\end{array}$ \\
\hline 9 & $\begin{array}{l}\text { A casa de Ana Neri. Texto elaborado pelo vigário de Cachoeira, Monsenhor Fernando Almeida Carneiro. } \\
\text { Documento, suporte papel. CDOC/EEAN/UFRJ. 04/02/1979 }\end{array}$ \\
\hline 10 & $\begin{array}{l}\text { Trasladação dos restos mortais de Ana Nery. Documento descreve processo de exumação no cemitério do Rio de } \\
\text { janeiro e pessoas envolvidas. Documento suporte papel, datilografado. 04/02/1979. Sem assinatura.CDOC/EEAN/ } \\
\text { UFRJ. }\end{array}$ \\
\hline 11 & $\begin{array}{l}\text { Cinzas de Ana Nery são entregues à terra natal. A Tarde. Recorte de Jornal, CDOC/EEAN/UFRJ, Caixa: Anna Nery. } \\
\text { 05/02/1979 }\end{array}$ \\
\hline 12 & $\begin{array}{l}\text { Ana Nery descansa em Cachoeira. Jornal da Bahia, Salvador - seção: Primeiro Caderno. Recorte de Jornal, CDOC/ } \\
\text { EEAN/UFRJ, Caixa: Anna Nery. 05/02/1979. }\end{array}$ \\
\hline 13 & $\begin{array}{l}\text { Helicópteros levam Ana Nery à Bahia. Jornal do Brasil - seção: Primeiro Caderno - segunda-feira, 05/02/1979. } \\
\text { Localização: Hemeroteca digital Biblioteca Nacional: http://memoria.bn.br/DocReader/030015_09/193922 }\end{array}$ \\
\hline 14 & $\begin{array}{l}\text { Adeus a Ana Neri. Autor: Dahas Zarur. Jornal do Commercio - seção } 1 \text { o Caderno - domingo, } 4 \text { e 2a feira, } \\
5 \text { de fevereiro de 1979. Localização: Hemeroteca digital Biblioteca Nacional: http://memoria.bn.br/ } \\
\text { DocReader/364568_16/62252 }\end{array}$ \\
\hline 15 & $\begin{array}{l}\text { Restos Mortais de Ana Nery acolhidos em sua terra natal. O Dia, Rio de Janeiro. Recorte de Jornal. CDOC/EEAN/ } \\
\text { UFRJ, Caixa: Anna Nery. 06/02/1979. data e identificação do jornal manuscrita. }\end{array}$ \\
\hline 16 & $\begin{array}{l}\text { A volta de Ana Nery segundo Edith Gama de Abreu: Cachoeira. Jornal da Bahia. Recorte de Jornal. CDOC/EEAN/ } \\
\text { UFRJ, Caixa: Anna Nery. 18/02/1979 }\end{array}$ \\
\hline 17 & $\begin{array}{l}\text { Retorna à Bahia Anna Nery "Mãe dos Brasileiros". Enfermagem - O Jornal Brasileiro de Enfermagem, Ano II, no 25, } \\
\text { p.1 e 4. Jornal, CDOC/EEAN/UFRJ, Caixa: Anna Nery. Abril de } 1979 .\end{array}$ \\
\hline 18 & $\begin{array}{l}\text { Do Rio à Bahia, pela FAB. Recorte de Jornal. CDOC/EEAN/UFRJ, Caixa: Anna Nery. Recorte sem data ou } \\
\text { identificação. }\end{array}$ \\
\hline
\end{tabular}

leva seu nome, em homenagem póstuma a uma mulher para além de seu tempo. Assim, Anna Nery, sobrevive por meio das justas homenagens e cerimoniais.

\section{CONCLUSÃO}

Imaginar que no século XIX, quando para a mulher brasileira era raro atuar como protagonista em uma sociedade de cultura tradicionalmente antifeminista, no que diz respeito à libertação intelectual, é de se ponderar como foi possível à Anna Nery, numa etapa do seu viver, viúva e com filhos na Guerra do Paraguai, encontrar forças para se dirigir em carta ao governo, deliberando-se a ir como voluntária a essa Guerra, representando e prestando serviços ao Brasil, seu país. E mais admirável ainda, conseguir assentimento com autoridade governamental para isto. Neste momento, 
irrompia-se a convicção da presença de uma semente do feminismo em terras brasileiras.

O traslado dos restos mortais de Anna Nery foi um evento que contou com o acolhimento da sociedade brasileira, efetivado, com honras de celebridade nacional, consolidando-a como heroína. A programação da trasladação dos restos mortais de Anna Nery, 165 anos após seu nascimento e 88 anos após seu sepultamento, trouxe à tona atos dignificados por uma mulher, enfermeira, nordestina e católica muito religiosa, com atributos altruístas em seu perfil, característico de uma certa identidade da Enfermagem brasileira, no início do seu desenvolvimento.

A grandiosidade de seus atos justifica ser reconhecida como personalidade da História da Enfermagem e congratulada heroína de guerra, mostrando que sua atuação fez a diferença no cenário em tela, a despeito do motivo que a tenha levado à guerra. Tal questão fortalece e consolida não só a identidade da profissão, como também a identidade de gênero.

A notoriedade de suas ações faz com que qualquer ato em relação à sua vida/morte seja registrado e referenciado, não passando em branco, por isso analisar a trasladação mostra a digna, merecida e impactante homenagem investida pelo governo brasileiro. Contudo, é válido destacar as limitações de estudos históricos, cujas críticas devem estar fundamentadas em documentos, fontes e estudos que muitas vezes estão indisponíveis e em outras ocasiões inexistem.

\section{CONTRIBUIÇÕES DOS AUTORES}

Concepção do desenho do estudo. Maria Angélica de Almeida Peres. Pacita Geovana Gama de Sousa Aperibense. Fernanda Batista Oliveira Santos.

Coleta de dados. Maria Angélica de Almeida Peres. Pacita Geovana Gama de Sousa Aperibense. Deybson Borba de Almeida. Fernanda Batista Oliveira Santos.

Análise de dados. Maria Angélica de Almeida Peres. Pacita Geovana Gama de Sousa Aperibense. Maria Lígia dos Reis Bellaguarda. Deybson Borba de Almeida. Fernanda Batista Oliveira Santos. Luciana Barizon Luchesi.

Interpretação dos dados. Maria Angélica de Almeida Peres. Maria Lígia dos Reis Bellaguarda. Deybson Borba de Almeida. Fernanda Batista Oliveira Santos. Luciana Barizon Luchesi.

Redação e revisão crítica do manuscrito. Maria Angélica de Almeida Peres. Pacita Geovana Gama de Sousa Aperibense. Maria Lígia dos Reis Bellaguarda. Deybson Borba de Almeida. Fernanda Batista Oliveira Santos. Luciana Barizon Luchesi.

Aprovação da versão final do artigo. Maria Angélica de Almeida Peres. Pacita Geovana Gama de Sousa Aperibense. Maria Lígia dos Reis Bellaguarda. Deybson Borba de Almeida. Fernanda Batista Oliveira Santos. Luciana Barizon Luchesi.

Responsabilidade pelo conteúdo intelectual. Maria Angélica de Almeida Peres. Pacita Geovana Gama de Sousa Aperibense. Maria Lígia dos Reis Bellaguarda. Deybson Borba de Almeida. Fernanda Batista Oliveira Santos. Luciana Barizon Luchesi.

\section{EDITOR ASSOCIADO}

Antonio José de Almeida Filho

\section{REFERÊNCIAS}

1. Padilha MI, Nelson S, Borenstein MS. As biografias como um dos caminhos na construção da identidade do profissional da enfermagem. Hist. cienc. saude-Manguinhos. 2011 dez;18(Suppl. 1):241-252. http:// dx.doi.org/10.1590/S0104-59702011000500013.

2. Amante LN, Padilha MI, Peres MAA, Gelbcke FL, Maia AR, Anders $\mathrm{JC}$ et al. A organização da enfermagem e da saúde no contexto da idade contemporânea (século XIX). In: Padilha MI, Borenstein MS Santos I, organizadoras. Enfermagem História de uma profissão. São Caetano do Sul, SP: Difusão Editora; 2011. p. 147-81

3. Cardoso MMVN, Miranda CML. Anna Justina Ferreira Nery: um marco na história da enfermagem brasileira. Rev. bras. enferm. 1999 set;52(3):339-48. https://doi.org/10.1590/S0034-7167199900030000.

4. Rodrigues MS. Mulheres sertanejas na Guerra do Paraguai. Anais do 6ํㅡㄹ Encontro da ANPHLAC; 2004; Maringá (PR), Brasil. Maringá (PR): USP; 2004. p. 1-11. [citado 2020 abr 9]. Disponível em: https://www. yumpu.com/pt/document/read/12842110/mulheres-sertanejas-naguerra-do-paraguai-anphlac.

5. Grisard N, Vieira ETS. Ana Néri, madrinha da enfermagem no Brasil Gaz Méd Bahia [Internet]. 2008 dez; [citado 2020 abr 9];78(2):145-47. Disponível em: http://www.gmbahia.ufba.br/index.php/gmbahia/article/ viewFile/981/959

6. Porto F, Oguisso T. Nome da "Mãe dos Brasileiros". Enfermagem em Foco. 20112(Suppl.):77-80. https://doi.org/10.21675/2357-707X.2011. v2.nSUP.87

7. Porto F. The Anna Nery National Museum of Nursing and the importance of historic preservation of. R Pesq.: Cuid Fundam. [Internet] 2010 out [citado 2020 abr 09];2(4):1191-1196. Disponível em: http://www.seer. unirio.br/index.php/cuidadofundamental/article/view/667

8. Veraldo TX, Porto FR, Passos AM, Rocha JÁ, Lima DM. Museu Nacional de Enfermagem Anna Nery: efeito esperado da exposição de longa duração. Rev enferm UFPE on line 2013 dez; [citado 2020 abr 12];7(esp):7254-7259. Disponível em: https://periodicos.ufpe.br/ revistas/revistaenfermagem/article/viewFile/12403/15181

9. Dias NL, Carvalho MS, Paim L, Aperibense PGGS, Peres MAA Monumentos e personagens históricos: preservação da identidade profissional da enfermagem em espaço acadêmico. Hist enferm Rev eletronica [Internet]. 2016 set; [citado 2020 abr 11];7(2):423-439. Disponível em: http://here.abennacional.org.br/here/2a05.pdf

10. Coelho CP. A Escola de Enfermagem Anna Nery: sua história - nossas memórias. Rio de Janeiro: Cultura Médica; 1997.

11. Porto F, Santos TCF. La romería al túmulo de D. Anna Nery (1925-1926): una tradición inventada para la enfermería brasileña. [Internet] 2005 set [citado 2020 abr 11];4(2):1-11. Disponível em: https://revistas.um.es/ eglobal/article/view/483/467

12. Porto F, Freitas GF, González JS. Fontes históricas e ético-legais: Possibilidades e inovações. Cul Cuid. [Internet]. 2009 [citado 2020 abr 9];23(25):46-53. Disponível em: https://rua.ua.es/dspace/ bitstream/10045/11539/1/CC_25_07.pdf

13. Bardin L. Análise de conteúdo. Tradução Luis Antero Reto, Augusto Pinheiro. São Paulo: Edições 70; 2016

14. Martins J. Del Golpe de 1964 al "Milagro Brasileño": la Campaña de la Mujer por la Democracia (CAMDE) - Acción política e imaginario colectivo. Iberoamérica Social. 2016 [citado 2020 abr 9]; 1 (esp):49-69. Available from: https://iberoamericasocial.com/ojs/index.php/IS/article/ view/276

15. Mota CG. História de um silêncio: a guerra contra o Paraguai (18641870) 130 anos depois. Estudos Avançados [Internet] 1995 [citado 2020 jul 01];9(24):243-254. Available from: https://www.scielo.br/pdf/ ea/v9n24/v9n24a12.pdf

16. Rodrigues MS. Os esquecidos da Guerra do Paraguai (1865-1875). Historiæ [Internet] 2014 [citado 2020 jul 1]; 5(1):164-183. Available from: https://periodicos.furg.br/hist/article/view/4811 
17. Rodrigues MS. Repercussões sobre o fim da Guerra do Paraguai, na Argentina, no Uruguai e no Brasil. Diálogos 2015 set/dez; 19(3):10651084. http://dx.doi.org/10.4025/dialogos.v19i3.1143.

18. Rodrigues MS. Ana Nery e outras tantas mulheres na guerra do Paragua (1865-1870). Rev. IGHB [Internet]. 2019 jan/dez [citado 2020 jul 6];114:265282. Available from: https://cfbc4640-f08f-4579-9718-412274f962ba. filesusr.com/ugd/4f3afO_ed3409b6160a4dc49b3b8acdddbde27c.pdf
19. Bastos Z. Biográfico de Anna Justina Ferreira e Anna Justina Ferreira Nery. Rev. IGHB [Internet]. 2019 jan/dez; [citado 2020 jul 6];114:39-60. Disponivel em: https://cfbc4640-f08f-4579-9718-412274f962ba.filesusr. com/ugd/4f3af0_ed3409b6160a4dc49b3b8acdddbde27c.pdf.

20. Quevedo J, Coelho M. O acontecimento Jango: exumação e memória na simultaneidade do jornalismo. Contracampo 2016;35(1):45-68. https://doi.org/10.22409/contracampo.v35i1.841. 